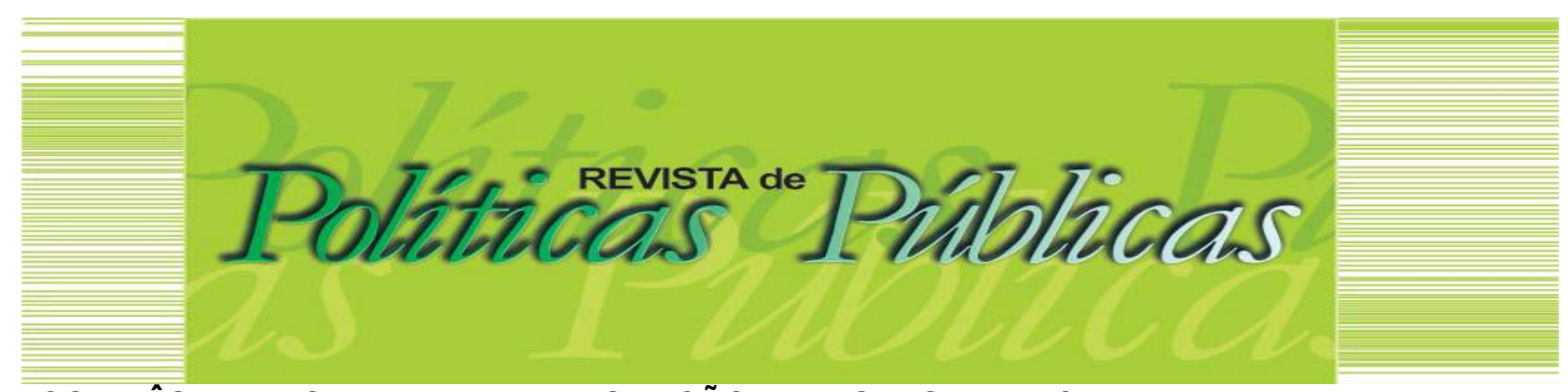

\title{
COMITÊS DE FRONTEIRA E A INTEGRAÇÃO TRANSFRONTEIRIÇA: possibilidades e impasses
}

Vera Maria Ribeiro Nogueira ${ }^{1}$ Helenara Silveira Fagundes ${ }^{2}$ Ineiva Teresinha Kreutz ${ }^{3}$

\section{Resumo}

Este texto aborda os Comitês de Fronteira, dispositivos legais e orgânicos ministeriais de cada Estado nacional em relação à ação federal nas franjas fronteiriças. Tem como objetivos resgatar os aspectos legais incidentes sobre as comissões de fronteira, a configuração das estruturas organizacionais e o impacto no alcance da proteção social na região. Obtém os dados documentais em banco de dados do Instituto Social do Mercosul sobre cidadania social em cidades gêmeas e realiza entrevistas com gestores das áreas da saúde e assistência social. Os resultados assinalam a diversidade existente entre as Comissões e o funcionamento distinto em termos de frequência de reuniões, pautas agendadas, relação com níveis hierárquicos. Apontam, ainda, para dificuldade de relação com as demais instâncias nacionais, a reduzida autonomia para acordos formais e reconhecimento regional.

Palavras chave: Integração transfronteiriça. Comissões de Fronteira. Proteção social em fronteiras. Paradiplomacia.

\section{BORDER COMMITTEES AND CROSS-BORDER INTEGRATION: possibilities and impasses}

\begin{abstract}
This paper addresses the Border Committees, legal and organic ministerial devices of each state concerned with federal action on border fringes. It aims to retrieve the legal factors impinging on such border commissions, the configuration of their organizational structures and their impact on the reach of social protection in the areas covered. Documentary data was obtained from the Mercosur Social Institute's database on social citizenship in twin cities. Interviews were also conducted with health and social care managers. The results, point to a diversity between committees, with distinct operations regarding frequency of meetings, scheduled agendas and relationship with hierarchical levels. They also suggest difficult relationships with other national bodies, reduced autonomy with regard to formal agreements and regional recognition.
\end{abstract}

Keywords: Cross-border integration. Border Commissions. Social protection at borders. Paradiplomacy.

Artigo recebido em: 15/01/2020 Aprovado em: 25/10/2020 DOI: http://dx.doi.org/10.18764/2178-2865.v24n2p600-618.

\footnotetext{
${ }^{1}$ Assistente Social, Doutora pelo Programa de Pós-Graduação em Enfermagem da Universidade Federal de Santa Catarina (UFSC), Professora do Programa de Pós-Graduação em Serviço Social da UFSC e do Programa de Pós-Graduação em Política Social e Direitos Humanos da Universidade Católica de Pelotas (UCPel). E-mail: veramrn@gmail.coml

2 Assistente Social. Doutora em Serviço Social pela Pontifícia Universidade Católica do Rio Grande do Sul. Professora Associada da Universidade Federal de Santa Catarina. E-mail: helenarasf@hotmail.com.

3 Assistente Social. Mestre em Educação Escolar Brasileira pela Universidade Federal de Goiás. Doutoranda do Programa de Pós-Graduação em Serviço Social da Universidade Federal de Santa Catarina. Professora do Curso de Serviço Social da Universidade Estadual do Oeste do Paraná (UNIOESTE), Campus de Toledo/PR, E-mail: ineivakreutz@gmail.com
} 


\section{INTRODUÇÃO}

Ao se pensar em processos de integração transfronteiriça deve-se recordar que as possibilidades, no presente, são decorrentes de iniciativas anteriores entre os países limítrofes, as quais foram permeadas por sucessos e retrocessos em face de determinações de ordem econômica, social, cultural e histórica. Atualmente os processos de descentralização dos países se tornam um elemento a mais para entender o protagonismo dos atores subnacionais em regiões fronteiriças através de ações diversas, entre elas as Comissões de Fronteira No caso em análise, as fronteiras internacionais se referem aos limites entre Argentina, Brasil, Paraguai e Uruguai. Destacam-se, inicialmente, as assimetrias entre estes países, seja em termos de linguagem, tamanho, história e cultura prevalente. Estas assimetrias igualmente traduzem processos de constituição política e econômica e impactam de forma distinta as institucionalidades e o padrão de integração entre os países em regiões fronteiriças.

A concepção de fronteira situa-se como outro determinante balizador do padrão de integração, sendo atualmente entendidas como transitivas e porosas, com uma territorialidade própria. Afasta-se da concepção anterior, dominante durante muito tempo, das fronteiras como limites instransponíveis e tratadas como áreas de segurança nacional. A partir dessas breves considerações, este texto aborda as Comissões ou Comitês de Fronteira, dispositivos legais e orgânicos ministeriais de cada Estado nacional em relação à ação estatal nas franjas fronteiriças tendo como eixo a forma de atenção à proteção social'1. Ou seja, em que medida as Comissões de Fronteira têm contribuído, e, de que forma, para 0 atendimento da população residente nas linhas de fronteira, quanto as suas necessidades básicas de proteção social pública. Busca identificar os impasses e possibilidades advindas destas Comissões. Esta abordagem é relevante na medida em que a população transfronteiriça busca proteção social nos dois países limítrofes, tanto devido à disparidade de ações e serviços oferecidos pelos países em relação aos sistemas protetivos, como pela distância da linha da fronteira dos centros maiores e mais bem equipados no quesito saúde e assistência em seus próprios países.

A preocupação com as Comissões de Fronteira decorre de estudos anteriores ao evidenciarem a falência de ações governamentais visando ampliar a cooperação transfronteiriça, visto que a partir das iniciativas de globalização, a fronteira passou a ser considerada como o primeiro degrau de integração. Houve uma reduzida alteração nos processos de inclusão pretendidos e as medidas implementadas, ao longo dos últimos quinze anos, ficaram distante dos resultados previstos pelos programas desenvolvidos na área (NOGUEIRA; FAGUNDES; AGUSTINI, 2015; NOGUEIRA; AGUSTINI, 2010; PREUSS, 2007; PREUSS; NOGUEIRA, 2012; FERREIRA; MARIANI, 
BRATICEVIC,2015; SILVA et al 2017; AIKE, 2017). Ou seja, as inovações institucionais, destinadas a favorecer a expansão e a articulação entre os sistemas protetivos das cidades localizadas nos limites internacionais, não conseguiram alterar o panorama quanto à garantia de saúde e assistência social no cenário transfronteiriço, exceto em algumas experiências positivas.

Uma das hipóteses levantadas para explicar o reduzido desempenho em nível local referese ao processo de implementação ${ }^{2}$ das políticas, aspecto que se destaca também, de forma recorrente, na literatura sobre avaliação de políticas públicas (COSTA; BRONZO, 2012; FARIA, 2012; FREY, 2000; BOUSSAGUET et al, 2010; MEGIE, 2010; BORRAZ; GUIRAUDON, 2008). E neste âmbito reside a relevância das Comissões de Fronteira e o maior conhecimento sobre sua estrutura legal e organizacional poderia contribuir para ampliar os processos de proteção social transfronteiriços.

Considerando o exposto anteriormente, estabeleceu-se como objetivo do texto resgatar os aspectos legais incidentes sobre as comissões de fronteira nos quatro países e a configuração das estruturas organizacionais existentes buscando identificar a razão das distinções em termos de alcance da cidadania social identificadas na região estudada.

Os dados documentais foram obtidos em um banco de dados construídos por ocasião de consultoria ao Instituto Social do Mercosul sobre cidadania social em cidades gêmeas da fronteira dos países integrantes do Mercosul. As principais fontes de dados secundários foram CEPAL, IPEA, páginas dos Ministérios Saúde e Assistência Social/Proteção Social dos quatro países, OPAS, UNASUR, ISAGG, INDEC, IBGE, Dirección de Estadísticas e Información en Salud - Ar, Instituto Nacional de Estatística - UY, Anuário Estatístico do Paraguai, Serviço de Processamento de Dados SERPRO; -Rede de Investigaciones en Sistemas y Servicios de Salud en el Cone Sur, Iniciativa de Integração da Infra-estrutura Regional Sul-americana -IIRSA; Observatório de Políticas de Fronteira CEFIR. Além dos dados documentais foram realizadas entrevistas com gestores das áreas da saúde e assistência social, nos marcos da mesma consultoria, no ano de 2017.

O texto foi organizado da seguinte forma: uma indicação do suporte teórico sobre implementação de políticas públicas e poder local utilizado para o resgate e a análise dos dados, os antecedentes históricos das Comissões de Fronteira, as medidas legais e os desenhos organizacionais e a experiência das Unidades Territoriais de Fronteira, como exemplo de experiências bem sucedidas.

\section{IMPLEMENTAÇÃO DE POLÍTICAS PÚBLICAS E PODER LOCAL}

O aprofundamento da compreensão sobre o processo de implementação trouxe outras nuances a serem apreendidas como, por exemplo, a indicada por Megie (2010) quanto à impossibilidade de uma abordagem exclusivamente top-down ou botton-up, devendo-se considerar 0 
conjunto de atores da ação pública e suas diferentes interdependências (verticais e horizontais). Esta perspectiva interacionista oferece a possibilidade de restituir a dimensão multinível e transversal da ação pública. Portanto, um mapeamento preciso de níveis de ação e competências governamentais, [...], bem como o papel e os interesses dos atores em presença é um trabalho essencial para compreender as interações sociais que estruturam o espaço público (MEGIE, 2010, p. 349). Nesta interação os diferentes níveis de ação pública são representativos e devem ser levados em conta, conforme a indicação de Borraz e Guiraudon (2008). Cada nível dispõe de competências diversas e as mudanças de escala - do global ao local, passando pelo nacional, tem um impacto na formulação da ação pública e na determinação da cidadania social. A apreensão destas interações deve levar em conta a convivência de competências distintas operando em um mesmo território, no caso particular das cidades gêmeas.

Por outro lado, o desconhecimento sobre essas estruturas administrativas e de gestão dos municípios vem sendo reafirmado por autores vinculados ao tema, alertando a predomínio de pesquisas sobre as burocracias nacionais, do alto escalão, em detrimento da análise dos dispositivos locais (CAVALCANTE; CAMÕES; KNOP, 2015; CAVALCANTE; LOTTA, 2015; OLIVEIRA; ABRUCIO, 2011; AlKE, FRIGOTTO, 2018). Alerta-se que a ampliação das decisões paradigmáticas na região estudada confirma esta assertiva, pois são recentes os estudos voltados para os atores locais neste espaço.

As decisões programáticas nacionais, ao serem direcionadas aos níveis subnacionais, não se limitam à implantação simplesmente, mas impõem novas decisões, e outros arranjos institucionais de cunho técnico e político são exigidos, ou seja, refaz-se a política no plano local, muitas vezes alterando completamente sua concepção inicial (LIPPI, 2007; BORRAZ; GUIRAUDON, 2010; SERAFIM, 2012; FARIA, 2012; HOWLETT; RAMESH; PERL,2013).

Em todos os países estudados os novos desenhos, relacionados à descentralização e à responsabilidade de gestão das políticas para o poder local, impõem aos gestores locais habilidade política e técnica tanto para compatibilizar os interesses locais, como para materializar as proposições federais, transformando-as efetivamente em políticas públicas na sua clássica acepção (HOWLETT; RAMESH; PERL, 2013). Enfatiza-se, assim, a relevância do agente estatal, pois sua ação tanto poderá favorecer os processos inclusivos para os não nacionais nos programas e serviços de proteção social, como barrar 0 atendimento em função de sua discricionariedade. É o momento da aplicação das decisões, o mis en oeuvre, caracterizando o momento em que a ação pública se confronta com a realidade através da aplicação das diretrizes governamentais (BOUSSAGUET; JACQUOT; RAVINET, 2010).

Transpondo para a situação dos limites internacionais, a questão que orientou a 
construção deste texto foi a de como os países organizaram, no plano jurídico e político-administrativo, os dispositivos que favorecem a integração transfronteiriça, com destaque para as Comissões de Fronteira.

Tomou-se como referência, indicativo da CEPAL, para se avaliar a institucionalidade social das políticas de proteção social - os elementos jurídico-normativos, organizacionais, técnico-operativas e ficais (CEPAL, 2016). Neste texto serão abordados os elementos jurídicos normativos e organizacionais.

Os elementos jurídicos normativos constituem a base legal da institucionalidade relacionada à garantia de direitos econômicos, sociais e cultural das populações adstritas a um estado nacional. Referem-se aos ordenamentos a partir dos quais vão se construindo as institucionalidades relativas às políticas estatais, vis a vis a cultura local, incorporando tanto a

[...] dimensión central para identificar los compromisos de los Estados con la garantía de derechos económicos, sociales y culturales de las personas. Incorpora la adhesión y ratificación de convenios y tratados internacionales, la garantía de derechos y la presencia de distintas temáticas sociales en los textos constitucionales, así como en las leyes y normativas específicas. Por tanto, incluye las leyes sociales sectoriales, en especial desarrollo y protección social, como también los planes nacionales de desarrollo social (CEPAL, 2017)

No caso estudado foi possível averiguar onde se localizam as desigualdades territoriais considerando-se a diversidade normativa dos países, expressas desde a atribuição de cidadania (jus solis e jus sanguini), a incorporação na ordenação jurídica de acordos e protocolos internacionais, as competências jurídicas em formalizar acordos bilaterais ou trilaterais pelos entes subnacionais, a regulação sobre migração até a delimitação da faixa de fronteira (oscilando entre 20 e 150 km2).

O segundo elemento apontado pela CEPAL para estudo da realidade local - a dimensão organizacional - é igualmente relevante, pois estabelece 0 trânsito entre a base normativa e a possibilidade material e estrutural das propostas programáticas em distintas instâncias governamentais. Diz respeito à configuração dos ministérios e instâncias do poder executivo competentes para implementar os programas de carácter social, a partir de seus mandados decorrentes da situação jurídica. A estrutura orgânica dos ministérios, secretarias, departamentos e municípios exige um certo "[...] grado de autonomia, especialización, relación e importância en comparación con otras áreas setoriais do governo." CEPAL, s/d). Entendendo a relação entre ministérios e municípios é que se buscou apreender a conformação dos primeiros direcionando a política local. 


\section{TRAJETÓRIA E DINÂMICA DOS COMITÊS DE FRONTEIRA NOS PAÍSES DO MERCOSUL}

Entre a Argentina e Brasil, em 19973, há a criação da Comissão de Cooperação e Desenvolvimento Fronteiriço (CODEFRO, 2016)4, integrada pela Argentina e Brasil, que deveria funcionar como instância de articulação política de alto nível, visando facilitar a execução de projetos e iniciativas de diversas áreas. Integrado por representantes ministeriais do governo central dos dois países, este Comitê vem desenvolvendo atividades e iniciativas de forma intermitente. Em sua segunda reunião, em outubro de 2013, implementou um convênio para investigação em saúde, formação de recursos humanos e desenvolvimento tecnológico em áreas de fronteira. Em 2017, os governos brasileiro e argentino reiteram o funcionamento do Comitê estabelecendo que a III Reunião do CODEFRO seria realizada em Foz do Iguaçu a fim de acompanhar e incrementar as iniciativas de integração fronteiriça entre os dois países, especialmente visando a implementação do Acordo sobre Localidades Fronteiriças Vinculadas e o Acordo sobre assistência em situações de emergência em zonas de fronteira. Observa-se o longo período entre uma reunião e outra, o que produz uma atuação frágil do CODEFRO, embora sua importância em termos de autoridades integrantes deva ser considerada. Não se encontrou informações correspondentes a outro tipo de articulação sobre o CODEFRO e como se processa a interiorização das decisões e propostas formuladas.

$\mathrm{Na}$ Argentina, a preocupação com a zona fronteiriça se manifesta através dos Comités de Integración Fronteriza, anteriormente denominados Comités de Frontera. Os primeiros comitês foram criados na fronteira com o Paraguai, em 1985, e consistiram em encontros binacionais que se realizam entre regiões fronteiriças. Ampliaram-se posteriormente para os demais países limítrofes com a Argentina, e têm como pauta temas de interesse mútuo relativos aos distintos setores da realidade local. Os Comitês de Integração se constituem em outra estratégia de cooperação transfronteiriça. Constituídos por representantes dos governos locais e entidades civis, têm um calendário de reuniões diversificado tanto em relação à temporalidade como em relação às cidades fronteiriças. Vem funcionando de forma regular na fronteira com o Uruguai. (ARGENTINA, 2018)

Es importante resaltar que los comités de integración no tienen capacidad de decisión, no son vinculantes, son una suerte de caja de resonancia de las estructuras públicas y privadas, con la preparación de propuestas para presentar ante los organismos correspondientes para su aprobación (MERCOSURABC).

A questão fronteiriça é igualmente tratada pelo poder executivo argentino a partir do Ministerio del Interior, Obras Públicas y Vivienda, na Secretaria de Interior, na Dirección de Asuntos Técnicos de Fronteras. Esta última coordena as ações desenvolvidas através dos organismos 


\section{COMITÊS DE FRONTEIRA E A INTEGRAÇÃO TRANSFRONTEIRIÇA: possibilidades e impasses}

nacionais relacionados aos compromissos firmados internacionalmente com respeito às áreas de fronteira.

Além da Diretoria, no início de 2017, foi criada uma Comisión Nacional de Fronteras, submetida à Chefatura de Gabinete dos Ministros. A Comissão tem como objetivo regular e coordenar o funcionamento dos principais pontos fronteiriços da Argentina, numa perspectiva interministerial, procurando facilitar o trânsito de pessoas, agilizar comércio e prevenir crimes internacionais. Foram criados 14 Centros de Fronteiras nas principais cidades.

A questão das fronteiras, no Paraguai, situa-se como responsabilidade do Ministério de Relaciones Exteriores através do Comités de Frontera e Integración. Grande parte das reuniões realizadas têm como objetivo as relações com Argentina. As atas dos encontros, disponíveis revelam o desenvolvimento de comissões de trabalho em várias áreas: Comisión de Facilitación Fronteriza (subcomisión de aduanas, migraciones, fito y zoosanitaria); Comisión de infraestructura; Comisión de transporte; Comisión de comercio y producción (subcomisión de turismo e industria); Comisión de desarrollo social (subcomisión de salud, educación y cultura); Comisión de género e Comisión de trabajo. Infere-se que os Comitês de Integração Fronteiriça para o Paraguai são de relativa relevância uma vez que não disponibilizam as atas das reuniões desde 2016, sendo obtidas pela publicação pelo Ministério das Relações Exteriores da Argentina. (PARAGUAl, 2018).

Especificamente em relação ao Brasil, ao regulamentar o território integrante da faixa de fronteira, com vistas a ocupar e fixar a população no território, o governo criou formas de garantir investimentos financeiros nesta região, segundo Pucci (2010), através de dois programas: o Programa de Desenvolvimento da Faixa de Fronteira (PDFF) e o Programa de Sustentabilidade dos Espaços Sub-Regionais (PROMESO). Estes Programas previam a constituição de espaços de debates transfronteiriços, ainda que de forma incipiente e com reduzida regulação.

Quando ocorre a mudança do governo de Fernando Henrique Cardoso para Luiz Inácio Lula da Silva, várias lacunas são apontadas no PDSFF, e se propõe sua reestruturação, superando aspectos negativos como a desarticulação entre os projetos, a perspectiva assistencialista dominante e "[...] a ênfase na ideia de fronteira como peça fundamental da defesa nacional e da imposição de barreiras às ameaças externas, implicando, de fato, a imposição de limites nas relações com os países vizinhos" (BRASIL, MIN, 2005, p. 5).

O programa volta a se chamar PDFF, e os investimentos na faixa de fronteira tiveram como atribuição desenvolver as regiões de fronteira com vistas ao estreitamento de laços com os países vizinhos. Essa reorientação do programa privilegia os acordos bilaterais enquanto modelos de atuação em conjunto que possam ser replicados em outros lugares. A partir desse eixo norteador, a faixa de fronteira do Brasil com os demais países é contemplada, além do PDFF, pelo Programa de 
Sustentabilidade dos Espaços Sub-Regionais (PROMESO). Este Programa ainda que não tenha sido instituído para as faixas de fronteira teve um impacto nas mesmas a partir de uma dimensão estritamente econômica, como se pode depreender de seu objetivo

[...] aumentar a autonomia e a sustentabilidade de espaços sub-regionais por meio da organização social, do desenvolvimento dos seus potenciais endógenos e do fortalecimento das suas bases produtivas, com vistas à redução das desigualdades inter e intra-regionais (BRASIL, MIN, 2009, p. 9).

Considerou-se importante destacar as iniciativas de cooperação transfronteiriça entre 0 Brasil e o Uruguai por dois fatos: o primeiro por ser uma linha de fronteira bastante porosa, com traços históricos de cooperação. O segundo pelos resultados positivos que foram observados em estudos recentes. Há que se ressaltar, entretanto, a impossibilidade de replicar as ações desenvolvidas nesta região em outras linhas de fronteira, servindo o detalhamento mais como uma ideia força a ser perseguida.

Inicialmente, deve-se observar que o Uruguai e Brasil mantêm relações de cooperação transfronteiriça de longa data, mas se apresentam aqui os passos mais recentes desta caminhada, já com uma perspectiva efetiva de integração.

Na década de 1990, assinala-se a Declaração de Jaguarão, que inaugurou os Comitês de Fronteira nas cidades gêmeas de Santana do Livramento/Rivera, Chuí/Chuy e Jaguarão/Rio Branco 5 , com os "[...] objetivos [de] impulsionar o desenvolvimento socioeconômico da região, promover a coordenação dos órgãos encarregados dos temas relevantes da área e facilitar a circulação de pessoas, mercadorias e veículos", que se reuniriam com a frequência necessária (BRASIL, 1990). Entretanto, possivelmente por não se ter estabelecido, na criação desses Comitês, um cronograma de reuniões para proposição de ações a serem realizadas em conjunto, os mesmos não se efetivaram como um locus privilegiado para promoção de discussões acerca de temas inerentes às fronteiras, embora quando da sua implantação fosse grande o afã e expectativa em torno de sua atuação. Aveiro (2006, p. 105) constata que, em geral, esses Comitês foram perdendo forças e suas reuniões foram se tornando mais esparsas, ou de fato tiveram atuação reduzida e pouco eficaz:

As reuniões dos Comitês foram, paulatinamente, sendo espaçadas. A empolgação inicial foi substituída por um sentimento de grande frustração. Embora as ideias dos comitês fossem boas, o organismo não era a instância capaz para executá-las. As recomendações eram enviadas aos Consulados, que tampouco eram as entidades competentes para implementálas. A burocracia envolvida em todo o processo inviabilizava 0 atendimento dos pedidos, 0 que desestimulava a continuação dos trabalhos locais. Além disso, a grande distância entre a esfera central e as localidades lindeiras dificultava ainda mais o desempenho positivo dos órgãos centrais e sua atuação efetiva. 
Diante da falência da proposta dos Comitês, em abril de 2002, ainda sob o governo de Fernando Henrique Cardoso no Brasil e Jorge Battle no Uruguai, é estabelecida uma "Nova Agenda de Cooperação e Desenvolvimento Fronteiriço", em que as demandas fronteiriças são tratadas sob uma nova ótica, pautada pelo desenvolvimento sustentável da região, com o objetivo de complementar e superar os impasses e entraves burocráticos. Visa coordenar a ação das diversas autoridades (AVEIRO, 2006).

Essa "Nova Agenda", segundo Aveiro (2006) e Simões (2012), é capitaneada pelo Ministério das Relações Exteriores dos países, que a mantém ativa através da atuação dos consulados e vice-consulados dispostos pela fronteira. As pautas são estruturadas e organizadas em quatro grupos de trabalho (GT): educação e formação profissional, saúde, saneamento e meio ambiente e cooperação policial e judicial, que realizam discussões e levam suas propostas para as Reuniões de Alto Nível (RAN), em que "[...] aprovam-se as propostas dos grupos de trabalho a serem remetidas às respectivas Chancelarias [e] têm a função precípua de informar e assessorar sobre 0 andamento das negociações bilaterais" (AVEIRO, 2006, p.116).

Aveiro (2006) sinaliza que os presidentes Luiz Inácio Lula da Silva (2003-2010) e Tabaré Vazquez (2005-2010) conduziram seus governos de forma a aprofundar as relações rumo à integração regional, qualificada esta iniciativa, pela autora, como uma reorientação da política externa brasileira.

No período 2005-2010 ocorreram modificações no conteúdo da agenda de integração regional produzindo impactos positivos na região de fronteira associando diversas dimensões da área social. Identifica-se a ênfase em ações na área da saúde, saneamento, meio ambiente, infraestrutura e cooperação policial e judicial. Nesse sentido se criam novos Grupos de Trabalho (GT), entre os quais estão a Saúde e a Comissão Binacional Assessora de Saúde.

No ano de 2004, também foi criado o Comitê Binacional de Intendentes e Prefeitos, que tem se reunido em algumas cidades da fronteira, congregando os municípios fronteiriços e planejando ações conjuntas. Essas reuniões têm ocorrido de forma a consolidar a "Nova Agenda", e na esteira dessas articulações, os Comitês de Fronteira deveriam retomar suas funções com o intuito de promover a discussão sobre novas áreas para integração.

\footnotetext{
Destas reuniões resultaram proposições de acordos que mais tarde seriam promulgados pelo governo brasileiro e uruguaio, como o de permissão de residência, estudo e trabalho, livre trânsito de pessoas, possibilitando que "[...] los antiguos 'indocumentados' ahora pueden vivir, estudiar, trabajar y tener acceso a la seguridad social en la zona de frontera de ambos países" embora este movimento ainda esteja longe de se concretizar como um bloco subregional (CLEMENTE, 2010, p.180).
}

Em abril de 2016, na X Reunião de Alto Nível da Nova Agenda de Cooperação e Desenvolvimento Fronteiriço Brasil - Uruguai, foi aprovado um novo Plano Integrado para a Fronteira, 
sendo os itens mais relevantes para este estudo os seguintes: desenvolver projetos visando à redução da informalidade nas relações de trabalho na zona fronteiriça, especialmente no setor agrícola; difundir adequadamente a informação sobre os direitos dos trabalhadores no Brasil e no Uruguai, bem como as políticas de trabalho decente executadas em todos os níveis de governo; fomentar ações e, eventualmente, propostas normativas para garantir os direitos dos trabalhadores contratados para atividades laborais de curta duração nos dois lados da fronteira; iniciar os diálogos para 0 estabelecimento de uma estratégia comum de combate ao tráfico de pessoas; firmar Memorando de Entendimento para a implementação conjunta do programa "Escolas Interculturais de Fronteira"; continuar as tratativas para a assinatura de Acordo que contemple a possibilidade de criação de cursos binacionais de graduação e pós-graduação; estimular, adicionalmente, a criação de programas de graduação e pós-graduação na região fronteiriça, inclusive na área de formação turística.

Paralelamente, o governo brasileiro, com o intuito de organizar as demandas e propostas de políticas para a região fronteiriça, em 2008, constitui, no âmbito do Ministério da Integração Nacional (MIN) do Brasil um Grupo de Trabalho Interfederativo (GTI), composto por representantes de alguns ministérios e municípios. O GTI sugeriu a criação por meio de decreto (BRASIL, 2010b), de uma Comissão Permanente para o Desenvolvimento e a Integração da Faixa de Fronteira (CDIFF), com a finalidade de "[...] propor medidas e coordenar ações que visem ao desenvolvimento de iniciativas necessárias à atuação do Governo Federal naquela região [...]" (BRASIL, MIN, 2010). Essa comissão é integrada por todos os ministérios do Governo Federal, estando prevista a participação dos representantes de municípios como membros convidados, e instalação de núcleos estaduais que sistematizarão e encaminharão as demandas locais, sendo compostos por atores envolvidos na região (Universidades, SEBRAE, governo estadual e federal, representantes das cidades-gêmeas, sociedade civil). (COMISSÃO PERMANENTE PARA O DESENVOLVIMENTO E A INTEGRAÇÃO DA FAIXA DE FRONTEIRA, 2010). O CDIFF se articula com Núcleos Estaduais aos quais compete sistematizar as demandas locais, analisar as propostas de ação e formular planos regionalizados de desenvolvimento. Destaca-se a possível distância entre o CDIFF e os Núcleos Regionais das faixas de fronteira, visto não ter sido mencionado por nenhum dos entrevistados em estudos anteriores, embora no Brasil, o Rio Grande do Sul e Santa Catarina contem com Planos Regionais de Integração da faixa da fronteira.

Pucci (2010) ressalta a atuação do Uruguai através do Ministério de Desarrollo Social (MIDES), através do "Programa de Frontera", que fomentou a criação de grupos de fronteira nas cidades-gêmeas, integrado por gestores locais, representantes da sociedade civil e do setor privado, no intuito de elaborar diagnósticos locais e discutir temas como saúde, educação, meio ambiente, cultura, proteção social, através de seminários temáticos. Embora primeiramente se pareça com a estrutura e os comitês de fronteira, sua diferença é que 
[...] os grupos de fronteira são canais nacionais de articulação com a sociedade local, geridos exclusivamente pelo MIDES; diferem, portanto, dos Comitês de Fronteira, que são órgãos binacionais, de composição menos aberta e bem mais formais em seus procedimentos (PUCCl, 2010, p. 44).

De acordo com Mallmann e Clemente, as relações entre Uruguai e Brasil podem ser classificadas em três momentos, ou gerações. As relações de primeira geração se iniciam em 1963, com o Acordo para a criação de uma comissão para aproveitamento da Lagoa Mirim. Em 1975 o tratado de Amizade e Cooperação já previu a instalação dos Comitês de Fronteira, com o início de funcionamento em 1993. Estes Comitês são coordenados pelos grupos consulares dos dois países, aos quais compete mobilizar e incentivar a participação de atores locais visando a construção de agendas a serem encaminhadas às instâncias superiores de integração. "A segunda geração de acordos binacionais de cooperação foi inaugurada com a Nova Agenda para Cooperação e Desenvolvimento Fronteiriço, firmada em 2002" (MALLMANN, CLEMENTE, 2017). A terceira geração tem início em 2012, com a redefinição dos termos da cooperação binacional, expressos no Comunicado Presidencial assinado pelos dois países e intitulado "Novo Paradigma para a Relação Brasil-Uruguai". Prevê o Plano de Ação para o Desenvolvimento Sustentável e a Integração BrasilUruguai, com a definição de ações a serem realizadas em áreas estratégicas, não se detendo diretamente na franja fronteiriça.

O programa "Políticas de Integração de Fronteira", implementado pela Direção de Descentralização e Participação do Ministério de Desenvolvimento Social e Participação do Uruguai, desenvolve atividades diversas e mantém um calendário de feiras como estratégia de integração.

O Uruguai possui outras comissões de fronteira, principalmente vinculadas ao Ministerio de Relaciones Exteriores, a saber: i) Dirección General del Área para Asuntos de Frontera, Limítrofes y Marítimos; ii) Dirección de Asunto de Frontera; iii) Comisión de Caracterización y Límites Frontera Uruguay-Brasil (CLUB); iv) Comisión Permanente de Cooperación para el Desarrollo de Zonas de Frontera Uruguay-Argentina (CODEFRO).

Dentre os Estados Parte do Mercosul, o Uruguai é o que implementa o maior número de ações visando a integração transfronteiriça via estratégias de intervenção territorial específica e referenciadas por diversos entrevistados.

\section{EXPERIÊNCIAS POSITIVAS DE INTEGRAÇÃO TRANSFRONTEIRIÇA}

A Unidade Temática de Fronteira - UTF, sob a responsabilidade do Ministerio de Desarrollo Social do governo uruguaio, tem como antecedente o "Programa Políticas de Integración de 
Frontera", citado anteriormente, desenvolvido entre 2006 e 2010, principalmente nas cidades gêmeas da fronteira uruguaio-brasileira (Chuy - Chui, Rivera - Livramento; Río Branco-Jaguarão; AceguáAceguá; Artigas-Quaraí e Bella Unión-Barra do Quaraí. O programa teve como objetivo geral: "Promover la mejora de la calidad de vida y el ejercicio de los derechos ciudadanos en el espacio territorial de frontera, desarrollando intervenciones integrales [...]. (DGNT; MIDES, 2012).

Entre 0 alcance do referido Programa se destacam: a conformação de grupos de fronteira ${ }^{6}$ e seu acompanhamento na elaboração de diagnósticos locais, a geração de espaços de articulação interinstitucional para resolução de problemas identificados, e a promoção do exercício dos direitos através da difusão dos acordos e regulamentações em vigor (DGNT; MIDES, 2012).

No marco do "Programa de Frontera", em 2010, foram criadas as Oficinas Binacionales de Atención Ciudadana (OB) do MIDES, mediante um convenio com a "Corporación Andina de Fomento" (CAF). O projeto tinha como objetivo melhorar o acesso à documentação, proteção social da população de fronteira, com ênfase nas populações empobrecidas. Finalizado o financiamento da CAF em 2012, foram fechadas as $\mathrm{OB}$ e, seus técnicos, integrados às Oficinas Territoriales (OT).

A reestrutura da qual resultou a criação da UTF, em 2012, dispôs que os temas de fronteira deixassem de ser temas das $O B$ para se tornarem assunto dos dispositivos territoriais da Dirección Nacional de Gestión Territorial-DNGT do Ministério de Desenvolvimento Social (MIDES). Assim, o Ministério definiu como uma de suas populações prioritárias para o quinquênio 2015-2020 à população em zonas de fronteira (DGNT; MIDES, 2016, p.1). Nesse cenário, com o objetivo de implementar uma agenda de cooperação fronteiriça com Argentina e Brasil, o MIDES apresentou as seguintes linhas orientadoras para 2016:

\footnotetext{
Participación en la X Reunión de Alto Nivel de la Nueva Agenda de Cooperación y Desarrollo Fronterizo Uruguay-Brasil realizada en Brasilia y aportes en la elaboración del Plan Integrado de Trabajo Uruguay - Brasil.

Acompañar actividades desarrolladas en zonas de frontera por el Alto Representante General del MERCOSUR en el marco del Sub Grupo de Trabajo no 18 de MERCOSUR Integración Fronteriza.

Desarrollo de encuentros bilaterales de cooperación con el Ministerio de Desarrollo Social de Argentina en base a la elaboración de una agenda binacional conjunta

Participación activa en las instancias de los Comités de Integración Uruguay-Argentina desarrolladas en la región de frontera litoral (DGNT; MIDES, 2016, p.3).
}

No Programa estabelecido, as abordagens para a população migrante e de fronteira são concebidas desde uma perspectiva de Direitos Humanos. Reconhece, o mesmo programa, que assumir uma "perspectiva fronteiriça-migratória" apresenta desafios específicos para as políticas sociais, pois implica em "[...] ampliar, incorporar e integrar en su diseño y alcance a sistemas territoriales que no están enteramente bajo jurisdicción de un único Estado y que presentan dinámicas singulares" (DGNT; MIDES, 2016, p. 2). 
Segundo informado em entrevista realizada com o responsável da Unidad de Asuntos Internacionales y Cooperación (UNASIC 2017, informação oral7), a agenda de trabalho, elaborada em coordenação com a UTF para 2016 e 2017, inclui ações nas linhas das normativas (Comité de Frontera e RAADH com Brasil, Comité de Integração e relatórios MIDES-MIDES com Argentina); de compromissos assumidos (definidos a partir de diferentes reuniões e intercâmbios com representantes de Uruguai e Argentina); de economia social (com o SEBRAE no Brasil); de Direitos Humanos (compartilhamento de agendas dos encontros Transforma - na área de diversidade sexual - com Argentina e Quilombo - sobre o afro - com Brasil); e de identidade (definição de procedimentos formais e informais, descentralização de residências, forma de registros, entre outros).

Por último, nos documentos consultados explicita-se a necessidade de incorporar a "[...] intersección de distintas institucionalidades, lo intra e inter ministerial, lo nacional y lo binacional", ao mesmo tempo que se procura avançar na articulação local-binacional e suas dimensões (DGNT; MIDES, 2016, p. 4). No que refere a instancias articuladoras específicas da UTF, na atualidade existe um grupo de trabalho em Rivera integrado por representantes institucionais do território e da sociedade civil, contando com o acompanhamento técnico da Unidade. Ao mesmo tempo, continuamente são realizados encontros com representantes dos países para tratamento de assuntos pontuais.

Outra experiência digna de destaque é a do Consórcio Intermunicipal da Fronteira (CIF). Embora atualmente não se caracterize particularmente como transfronteiriça, como foi sua intencionalidade inicial, a menção a este se deve ao fato de constituir-se em uma tendência futura deste tipo de ação. A descontinuidade desta intenção parece ocorrer devido a questões legais do Brasil, no momento da formalização jurídica do CIF, quando foi excluído o município de Bernardo de Irigoyen, contrapondo-se aos documentos iniciais da sua constituição.

O Consórcio Intermunicipal de Fronteira decorre de iniciativas dos atores políticos governamentais e não governamentais dos municípios de Dionísio Cerqueira, Barracão e Bom Jesus do Sul (Brasil) e Bernardo de Irigoyen (Argentina). Em termos jurídico-administrativos situa-se como Associação Pública com Personalidade Jurídica de Direito Público e Natureza Autárquica, integrado pelos municípios brasileiros. Contrariamente ao mencionado em seu protocolo de intenções, a inclusão de Bernardo de Irigoyen (Argentina) no Gabinete de Gestão Integrada Intermunicipal, não permanece esta situação no Estatuto aprovado em 2009, sendo integrada unicamente por municípios brasileiros.

Tem, portanto, como intencionalidade última, ampliar o desenvolvimento econômico e social da região, com os objetivos de intensificar o desenvolvimento regional; buscar soluções para os problemas comuns dos municípios envolvidos através de soluções comuns e ampliação da capacidade técnica, gerencial e financeira por meio de alianças que possibilitem a melhoria e qualidade na prestação dos serviços públicos. (CONSÓRICO INTERMUNICIPAL DA FRONTEIRA, 2017). 
Organiza, também, suas ações em áreas temáticas, a saber: desenvolvimento regional incluindo o turismo, educação, saúde, agroecologia e produtos locais. (http://cifronteira.com.br/projetose-obras/, 2017). Na área da Educação informam, através da web, as ações no sentido de implementar educação bilíngue nas escolas locais; a formação integrada de professores e implantação do Programa Mais Educação. Quanto ao Turismo, há a proposta de instalação do Parque Turístico Ambiental de Integração, sem informações recentes quanto à sua concretização. Em relação à saúde, mencionam 0 projeto de reforma do Hospital Municipal de Dionísio Cerqueira; programa de transporte integrado de pacientes entre as cidades de referência para média e alta complexidade e o Programa para possibilitar o repasse de recursos do Fundo para a Convergência Estrutural do Mercosul -FOCEM, governos federal e estaduais para custeio de atendimento hospitalar.

As ações do Consórcio se voltam para o desenvolvimento dos municípios brasileiros, não havendo menção específica sobre articulação com o congênere argentino. Não há dúvida que a educação bilíngue irá favorecer a integração binacional, sendo uma iniciativa promissora.

Cabe destacar que em estudos anteriores se identificaram ações concretas de cooperação em saúde a partir dos profissionais da área, os quais chegaram a pactuar protocolos de atendimento entre Bernardo Irigoyen e Dionísio Cerqueira. Observa-se ter sido esta iniciativa possível devido à existência do Pacto pela Saúde - Normativa do governo brasileiro, viabilizando a integração com outro país a partir da concepção de região sanitária. Esta experiência foi interrompida a partir da alteração da gestão municipal com outras prioridades, devido à inexistência de pactos formais e do novo pacto de regionalização em 2011, impondo restrições para constituição das regiões sanitárias com países limítrofes.

\section{CONSIDERAÇÕES FINAIS}

As iniciativas locais, mesmo não sendo em sua totalidade decorrentes das Comissões de Fronteiras e mais dos agentes públicos locais, podem resgatar fatos e elementos que sinalizam para as potencialidades locais.

Em primeiro lugar há a intencionalidade manifesta pelos gestores de integração transfronteiriça na perspectiva dos direitos humanos, embora nem sempre acompanhada de ações concretas. Destaca-se a articulação institucional para o atendimento conjunto em casos de violação de direitos de crianças e adolescentes, ainda que através de acordos informais identificados em várias cidades gêmeas. Outro destaque são as experiências inovadoras do setor educacional, favorecendo a construção em médio e longo prazo de uma ideologia de integração, tanto devido à relevância de ações multiescalares quanto da iniciativa dos profissionais de educação em nível local; 
No quesito proteção social há a preocupação com o tráfico de pessoas nas fronteiras internacionais, especialmente de mulheres, crianças e adolescentes, secundado pela importância da documentação com o desenvolvimento de estratégias para solucionar a questão da população sem documento de identidade, exigido para acesso a alguns benefícios sociais.

Um ponto relevante na trajetória de ampliar o trânsito transfronteiriço reside no reconhecimento entre os integrantes das Comissões de Fronteira entre Argentina e Uruguai da importância de se ter um procedimento comum, garantindo direitos equitativos em todas as passagens fronteiriças, garantindo o direito do trabalhador e favorecendo as trocas comerciais.

Ademais dos aspectos positivos, foram constatadas questões a serem superadas para ampliação da proteção social em áreas de fronteira. O primeiro e mais crucial ponto é a distância entre o proposto nos Acordos e Normativas e sua efetivação em nível local, tanto pelo desconhecimento dos mesmos por grande parte dos entrevistados, à exceção da fronteira uruguaia, como pela distância dos centros decisórios nacionais.

Há uma grande fragilidade nos encaminhamentos do poder público federal em relação às fronteiras, à exceção do Uruguai, devido à distância dos centros decisórios e administrativos vis à vis a reduzida influência de atores locais para inserir as preocupações fronteiriças na agenda pública. As Comissões brasileiras e argentinas são constituídas por representantes ministeriais residentes nas capitais dos países e com pouca inserção nas questões de fronteiras.

A impossibilidade dos municípios fronteiriços serem abordados em termos de políticas públicas de maneira uniforme em decorrência de suas peculiaridades leva a acordos informais no âmbito da paradiplomacia, ocorrendo a descontinuidade de ações exitosas em razão de crises e alterações políticas e econômicas nacionais e locais, reduzindo ou mesmo anulando processos transfronteiriços inclusivos.

A convivência de sistemas e estruturas governamentais distintos em um mesmo espaço geográfico, exigindo dos gestores governamentais locais a implementação de ações nem sempre condiz com o ordenamento jurídico nacional, fato que vem sendo pouco debatido nas Comissões de Fronteiras. Ocorre a fluidez das determinações dos Comitês de Integração devido à ausência de um ente nacional ou estadual para transpor as propostas para ação, com competência executiva.

A ausência de uma institucionalidade mais efetiva das relações estabelecidas, especialmente nas Comissões de Fronteiras, sem independência para executar ações e recursos de infraestrutura e materiais para implementar as decisões tomadas em outras instâncias, parece ser o maior impasse relacionado às Comissões de Fronteiras e outras redes transfronteiriças existentes. Tal fato não ocorre unicamente na fronteira com o Uruguai, mas, também, com as Unidades Territoriais de Fronteira. 
As assimetrias entre as cidades gêmeas, o que inviabiliza propostas de ações para a linha de fronteira como um espaço homogêneo vis à vis a ausência de estudos mais detalhados, de ordem qualitativa para identificar os espaços de possíveis convergências e as dinâmicas locais.

Para superar os resultados limitados das decisões das Comissões de Fronteiras e de outras redes territoriais transfronteiriças um caminho promissor seria ampliar as articulações entre os níveis hierárquicos do poder público superando o descompasso entre as agendas nacionais e locais. Em outros termos

[...] enquanto os Estados desenvolvem "la diplomacia de los grandes acuerdos" os atores locais implementam "una gobernanza paso a paso" que necessitaria "reconocimiento formal del Estado, en tanto aumento de la trama legal de procedimientos de regulación para la elaboración de políticas públicas en sentido de interdependencia transfronteriza (MALLMANN, CLEMENTE, 2017, p. 12).

A pulverização das ações setoriais, aliada à reduzida capacidade de gestão operativa das Comissões de Fronteiras e mesmo de outras redes poderia ser superada com a indicação de uma coordenação local com funções para além de debater e propor ações transfronteiriças, ter competência para articular iniciativas das distintas esferas de governo representadas nas cidades da linha da fronteira.

\section{REFERÊNCIAS}

AlKE, S. Dinâmicas de integração e o acesso à saúde em cidades gêmeas do Paraná. Dissertação (Mestrado em Saúde Pública em Região de Fronteira). UNIOESTE. 2017.

AIKES, S; FRIGOTTO, M. L. Integração regional em cidades gêmeas do Paraná, Brasil, no âmbito da saúde. Cad. Saúde Pública, n.34, v.8, 2018.

ARGENTINA. Ministério das Relações Exteriores. Disponível em: https://integrac-

fronteriza.cancilleria.gob.ar/brasil/puerto-iguazu-foz-de-iguazu. Acesso em: 28 mar. 2019.

AVEIRO, Thais Mere Marques. Relações Brasil-Uruguai: A Nova Agenda para a Cooperação e o Desenvolvimento Fronteiriço. 238p. Dissertação (Mestrado em Relações Internacionais) - Programa de Pós-Graduação em Relações Internacionais, Instituto de Relações Internacionais, Universidade de Brasília, Brasília, 2006. Disponível em: http://repositorio.bce.unb.br/bitstream/10482/2342/1/2006_ThaisMereMAveiro_orig.pdf . Acesso em: 04 jun. 2011.

BORRAZ, O; GUIRAUDON, V. Changer La societé. Politique publique. Paris: Presses de la Fondation Nationale des Sciences Politiques. 2010.

BOUSSAGUET, L.; JACQUOT, S.; RAVINET, P. Dictionnaire des politiques publiques. Paris: Presses de Science Po. 2010. 
em: http://www.integracao.gov.br/publicacoes/programasregionais/livro.asp . Acesso em: 12 nov. 2010.

BRASIL. Presidência da República. Casa Civil. Decreto de 8 de setembro de 2010. Institui a Comissão Permanente para o Desenvolvimento da Faixa de Fronteira - CDIF. Disponível em: http://www.planalto.gov.br/ccivil 03/ Ato2007 -

BRASIL. Declaração do Jaguarão. 1990. Disponível em: http://www2.mre.gov.br/dai/b-urug 210.pdf. Acesso em: 5 jul. 2011.

BRASIL. Ministério da Integração Nacional. Programa de Desenvolvimento da Faixa de Fronteira. Disponível em:

http://www.integracao.gov.br/programas/programasregionais/faixa/objetivos.asp?area=spr_fronteira . Acesso em: 12 nov. 2010.

BRASIL. Ministério do Desenvolvimento Social. Página Inicial. Obtido em internet em http://www.desenvolvimentosocial.sp.gov.br/a2sitebox/arquivos/documentos/833.pdf >. Acesso em: 2 mar. 2017.

CAVALCANTE, P. L.; CAMÕES, M. R. S.; KNOP, M.N.H. Burocracia de médio escalão nos setores governamentais: semelhanças e diferenças. In: CAVALCANTE, P. L.; LOTTA, G. S. Burocracia de médio escalão: perfil, trajetória e atuação. Brasília: ENAP, 2015.

CEPAL. Institucionalidade social para a América Latina y Caribe. Obtido em http://dds.cepal.org/bdips/index.php. Acesso em: 20 fev. 2016.

CODEFRO - Comisión de Cooperación y Desarrollo de Fronterizo. Obtido em Internet em http://www.msal.gob.ar/inmet/index.php/27-pagina-inicial/517-noticia-codefro. Acesso em: 21 set. 2017.

COSTA, B. L. D., BRONZO, C. Intersetorialidade no enfrentamento da pobreza: o papel da implementação e da gestão. In: FARIA, C. A. P. (org.). Implementação de políticas públicas: Teoria e prática. Belo Horizonte: PUCMinas, 2012.

FARIA, C. A. P. (org.) Implementação de políticas públicas: Teoria e prática. Belo Horizonte: PUCMinas, 2012.

FERREIRA, C. M. P. G.; MARIANI, M. A. P.; BRATICEVIC, S. I. As múltiplas fronteiras presentes no atendimento à saúde do estrangeiro em Corumbá, Brasil. Revista Saúde Sociedade, v. 24, n. 4, p. 1137-1150, 2015.

FREY, K. Políticas Públicas: um debate conceitual e reflexões referentes à pratica da análise de políticas públicas no Brasil. Planejamento e Políticas Públicas, n. 21, p. 211-259, jun. 2000.

HOWLETT, M., RAMESH, M. PERL, A. Política Pública: seus ciclos e subsistemas - uma abordagem integral. Rio de Janeiro: Elsevier, 2013.

IBGE. Instituto Brasileiro de Geografia e Estatística. População brasileira. Cidades. Disponível em: https://cidades.ibge.gov.br/. Acesso em: 23 set. 2017.

IPEA. Fronteiras do Brasil: diagnóstico e agenda de pesquisa para política pública. v.2. Brasília: Ipea: MI, 2017. 
LIPPI, A. La valutazione delle politiche pubblicque. Bolonha. II Mulino. 2007.

MALLMANN, Maria Izabel; CLEMENTE, Isabel. Descentralização e federalismo em processos de cooperação transfronteiriça. $O$ caso de Brasil e Uruguai. Trabalho preparado para apresentação no $9^{\circ}$ Congresso Latinoamericano de Ciência Política, organizado pela Associação Latino-americana de Ciência Política (ALACIP). Montevidéu, 26 ao 28 de julho de 2017.

MERCOSURABC. Los Comités de Integración como Importante Mecanismo de Relacionamiento Bilateral. Disponível em: http://www.mercosurabc.com.ar/nota.asp?ldNota=3025\&IdSeccion=7 .Acesso em: 21 set. 2017.

MEGGIE, A. Mise em Oeuvre. Um moment de L'action publique. In: BOUSSAGUET, L.; JACQUOT, S.; RAVINET, P. Dictionnaire des politiques publiques. Paris: Presses de Science Po. 2010.

NOGUEIRA, V. M. R.; AGUSTINI, J. A descentralização da política nacional de saúde nos sistemas municipais na linha da fronteira MERCOSUL. Serviço Social e Sociedade. v. 102. 2010.

NOGUEIRA, V. M. R.; SILVEIRA, H. F.; AGUSTIVI, J. A institucionalidade dos sistemas sanitários locais nas linhas da fronteira: impactos no acesso aos serviços e ações de saúde. Revista Brasileira de Monitoramento e Avaliação, 2015.

OLIVEIRA, V. E.; ABRUCIO, F.L. Entre a política e a burocracia: a importância dos burocratas de nível médio para a produção de políticas públicas em saúde e educação. In: Encontro Anual da ANPOCS, 35, Caxambu, MG, 2011. Disponível em:

www.sigeventos.com.br/anpocs/inscricao/resumos/0004/tbr2707-1.doc. Acesso em: 10 maio 2011.

PARAGUAI. Ministério das Relações Exteriores. Atas das reuniões Comissões de Integração Transfronteiriça. Disponível em: http://www.mre.gov.py/v2/Home/Contenido/574. Acesso em; 10 nov 2018.

PIGNA, F. História da Argentina. Disponível em: https://www.elhistoriador.com.ar/._Acesso em: 17 out. 2018.

PREUSS, L.; NOGUEIRA, V. M. R. O pacto pela saúde nas cidades-gêmeas da fronteira do Rio Grande do Sul com a Argentina e o Uruguai. Textos e Contextos, 2012.

PREUSS, Lislei Terezinha. 0 direito à saúde na fronteira: duas versões sobre o mesmo tema.

Dissertação (Mestrado em Serviço Social) Universidade Federal de Santa Catarina, Florianópolis, 2007.

PUCCI, Adriano Silva. 0 estatuto da fronteira Brasil-Uruguai. Brasília: FUNAG, 2010.

SERAFIM, M. P., DIAS, R. de B. Análise de Política: Uma Revisão da Literatura. Cadernos Gestão Social, v.3, n.1, p.121-134, jan/jun 2012. www.cgs.ufba.br.

SILVA, M. G. Serviço Social e Saúde: o exercício profissional do Assistente Social em Região de Fronteira In: Saúde e trabalho em Múltiplas Perspectivas.1 ed. São Paulo: Plêiade, 2011, p. 305330.

SIMÕES, Antônio José Ferreira. Eu sou da América do Sul. Brasília: FUNAG, 2012. Capítulo 3. Brasil e Uruguai sob o signo da solidariedade e do pragmatismo, p. 47-62. 
URUGUAI. Instituto Nacional de Estadística (INE). Disponível em: www.ine.gub.uy. Obtido em 18 de janeiro 2017.

URUGUAI. Dirección General de Estadística, Encuestas y Censos. Disponível em https://www.dgeec.gov.py/. Acesso em: 12 de dezembro de 2017.

\section{Notas}

1 Como proteção social considera-se toda a atenção dispensada à população economicamente vulnerável (assistência social), crianças e adolescentes em situação de risco e proteção à saúde através da oferta de ações e serviços de saúde em todos os níveis.

2 A implementação é considerada um momento da ação pública e constitui o processo de aplicação das decisões e caracteriza o momento que as decisões se confrontam com a realidade (BOUSSAGUET; JACQUOT; RAVINET, 2010, p. 343).

${ }^{3} 0$ governo brasileiro promulgou a criação do CODEFRO através do decreto $n^{0} 3078$, de $1^{\circ}$ de julho de 1999.

${ }^{4}$ Em alguns textos há a indicação do Uruguai participando também do CODEFRO.

${ }_{5}^{5}$ Para uma abordagem mais detalhada dessa legislação ver a dissertação de AVEIRO, Thais Mere Marques. Relações Brasil-Uruguai: A Nova Agenda para a Cooperação e o Desenvolvimento Fronteiriço".

${ }^{6}$ No documento de referência explicitam-se os seguintes eixos temáticos: cidadania, trabalho, proteção social, saúde, educação, desenvolvimento local, meio ambiente, complementação de serviços e cultura.

${ }^{7}$ Entrevista [jul. 2017]. Entrevistador: pesquisador da consultoria. Montevidéu. 